REFERENCES

DESIDERATO, O. Generalization of conditioned suppression. Journal of Comparative \& Physiological Psychology, 1964, 57, 434-437.

de TOLEDO, L., \& BLACK, A. H. Heart rate: Changes during conditioned suppression in rats. Science, 1966, 152, 1404-1406.

HAMMOND, L. J. Increased responding to CS - in differential CER. Psychonomic Science, 1966, 5, 337-338.

HEARST, E.S. Approach, avoidance, and stimulus generalization. In D. I. Mostofsky (Ed.), Stimulus generalization. Stanford: Stanford University Press, 1965.
RAY, O. S., \& STEIN, L. Generalization of conditioned suppression. Joumal of the Experimental Analysis of Behavior, 1959, 2, 357-361.

SIEGEL, S. Nonparametric statistics for the behavioral sciences. New York: McGraw-Hill, 1956.

NOTE

1. Supported by Research Grant GB-5694 from the National Science Foundation to Robert $C$. Bolles, principal investigator. His guidance in carrying out this investigation is gratefully acknowledged.

\title{
Cross-modal transfer of a specific discrimination in the rabbit
}

\author{
ARTHUR L. YEHLE and JEANNETTE P. \\ $W A R D$, Memphis State University, \\ Memphis, Tenn. 38111
}

Classical discrimination conditioning was employed to establish a discrimination between two rates of intermittent stimulation in the auditory modality for two rabbits and in the visual modality for two additional rabbits. Acquisition of the initial discrimination was facilitated in the auditory condition. Following training in the original modality, the stimulus modality contingencies were exchanged and a test of transfer conducted. Transfer from audition to vision and from vision to audition was definitively shown by both the heart-rate and eyeblink responses.

The ability to discriminate immediately some dimension of stimuli in one sense modality after previous training on the same dimension in an alternative sense modality constitutes the phenomenon of cross-modal transfer of a specific discrimination. This ability has been demonstrated in humans under a variety of test situations (Gaydos, 1956; Sinha \& Sinha, 1960; Blank \& Bridger, 1964; Blank, Altman, \& Bridger, 1968). Tests, however, of nonhuman primates have yielded results indicating either no cross-modal transfer (Burton \& Ettlinger, 1960; Ettlinger, 1960; Rothblat \& Wilson, 1968 ) or merely some facilitation of the discrimination in the second modality (Wilson \& Shaffer, 1963; Blakeslee \& Gunter, 1966). No animal study to date has reported complete and immediate transfer of a specific discrimination across sensory modalities.

Results of previous studies have supported the proposal of a dichotomy of cross-modal capabilities between man and lower animals related to the presence of language abilities in man and the absence of symbolic language in lower animals (Geschwind, 1965; Ettlinger, 1967). However, the acceptance of a clear-cut dichotomy in this respect would be premature in view of the limited number and scope of studies in this area. In the present study, the ability to transfer a specific discrimination from the visual modality to the auditory and the converse was assessed in another species of mammal, the rabbit, in a classical discrimination conditioning task using intermittent auditory and visual stimulation.

\section{METHOD}

The Ss were four New Zealand albino rabbits, approximately $3 \frac{11}{2}$ months old and weighing approximately $5.5 \mathrm{lbs}$. Each $S$ was caged individually and had free access to food and water.

During training, Ss were restrained in a Plexiglas box which was placed in a dark, ventilated, sound-attenuated chamber. The eyeblink (EB) response was recorded by using Wireform connectors soldered to stainless steel wound clips affixed $10 \mathrm{~mm}$ from the posterior edge of the rabbit eye. (This response measure is similar to that discussed by Vandercar, Swadlow, Elster, \& Schneiderman, in press.) Two stainless steel safety pins were inserted into the skin of each $S$ to record heart rate (HR).

The CSs were either $700-\mathrm{Hz}$ tone pips presented to $S$ through a 6-in. speaker, located 4 in. above the $S$, or light flashes from a $28-\mathrm{V}$ incandescent bulb located similarly. The US, a $0.3-\mathrm{sec}$ duration constant-current electric shock, was administered through the recording clips described above. In order to maintain a stable level of response, shock intensity was varied from 2 to $12 \mathrm{~mA}$ over days. The CS duration was $2.3 \mathrm{sec}$ and the offset of the CS was coincident with the offset of the US on CS+ trials. The intertrial interval was $69 \mathrm{sec}$.

Initial discrimination conditioning was with auditory stimuli for two Ss and with visual stimuli for two other Ss. For both the auditory and visual conditions CS+ was composed of intermittent stimuli at the rate of $8 / \mathrm{sec}$ with a duration of $2 \mathrm{msec}$ and $\mathrm{CS}$ at $2 / \mathrm{sec}$ with a duration of $4 \mathrm{msec}$. At the completion of initial conditioning, stimulus modality contingencies were exchanged for the two groups and discrimination conditioning continued in a test of transfer.

Conditioning consisted of 1 day of adaptation, 13 days of classical discrimination training, and 3 days of transfer training. During each daily session, Ss received 24 trials with the CSt and 24 trials with the CS-randomly presented with the restriction of no more than two similar trials in succession. Trials 11 and 12,23 and 24,35 and 36 , and 47 and 48 were designated as test trials (no US) and used to assess $\mathrm{HR}$ responding to the $\mathrm{CS}+$ and the CS- by measuring the distance between 10 successive heart beats prior to CS onset and comparing this with the measurement of 10 successive heart beats immediately following CS onset. A per cent change from baseline was then calculated and used as a measure of HR-CRs. The EB responding was measured on every trial and a $5-\mathrm{mm}$ pen deflection, corresponding to an approximately one-third eye closure, with a latency less than $2 \mathrm{sec}$, was used as a criterion for a conditioned EB response. RESULTS AND DISCUSSION

Initial discrimination conditioning was facilitated when the CS was stimulation in the auditory modality. The superiority of auditory stimuli over visual stimuli in effecting a response in the rabbit has been noted previously by Monnier \& Gangloff (1961) for an electrographic arousal response. In the present study, the discrimination of intermittent tones as measured by HR responding was established during the first session and was maintained throughout the subsequent conditioning sessions. The EB response appeare d earlier in conditioning and with greater frequency of occurrence to intermittent auditory stimulation than to corresponding visual stimulation

Nondifferential HR responding to visual stimuli appeared early in conditioning, but discrimination of $\mathrm{CS}+$ and $\mathrm{CS}-$ did not begin until Day 8. EB responding to visual stimuli also appeared later in conditioning and responding was infrequent relative to that seen in the auditory conditioning. For the rabbit, discrimination of intermittent visual stimuli was more difficult under these conditions of testing than discrimination of similar intermittent auditory stimuli. 


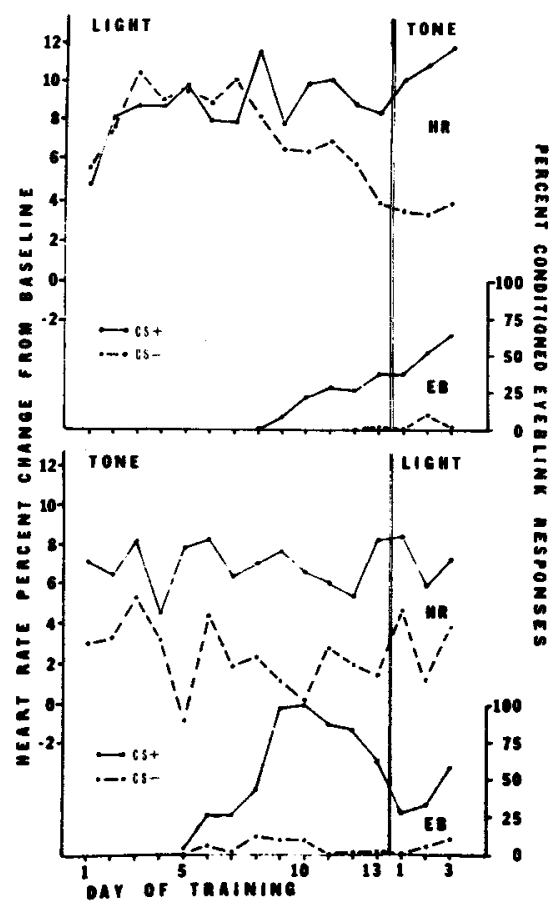

Fig. 1. Mean HR and EB responses to CS+ and $C S-$ in initial and transfer training with aditory and visual stimuli.

Whether the discrimination was established early, as in the auditory condition, or late, as in the visual condition, $H R$ responding over base level $H R$ appeared on the first session and was maintained throughout conditioning and transfer at the same high level. On the other hand, for both modality conditions the $\mathrm{EB}$ response appeared late in conditioning and frequency of the occurrence of the response was low. These divergences between $\mathrm{HR}$ and EB responding previously reported by Yehle (1968) are a function of the interstimulus interval of $2.0 \mathrm{sec}$ which has been shown to favor HR responding and result in decreased levels of the more rapid eye response (Vandercar \& Schneiderman, 1967).

As measured by both $H R$ and EB responding, it appears (Fig. 1) that cross-modal transfer of a specific discrimination was effected. For both response systems, the discrimination of intermittent stimuli was maintained from the first day of transfer training to the last, whether the transfer was from vision to audition or the converse.

Transfer of the discrimination of two rates of intermittent stimulation in audition to the visual modality is most definitive. Although initial discrimination of the light flashes required many sessions of training, Ss previously trained to discriminate intermittent tones, immediately differentiated the two corresponding rates of light flash as indicated by both $\mathrm{HR}$ and EB responding. Thus, as a consequence of the prolonged training required in acquisition of the visual discrimination, the immediate discrimination of light flashes in the transfer condition following training with tone pips constitutes strong evidence that transfer of a specific discrimination has occurred.

One valid criticism that may be offered for any test of transfer across modalities is that what appears to be transfer may simply represent very rapid acquisition in the second modality. Indeed, it may be seen here that such a difficulty exists in the assumption of transfer from vision to audition as indicated by $H R$ responding.

In initial training, the tone discrimination was established by the HR response on the first session. This rapid acquisition of the auditory discrimination, as indicated by the HR response, might render suspect the presumption that transfer has occurred from vision to audition. However, the EB response which did not appear in initial auditory training until the fifth session was as well maintained as HR responding in Ss presented auditory stimuli for the first time in the transfer condition following training on visual stimuli. Thus it is concluded that transfer did occur from vision to audition as well as from audition to vision.

The successful demonstration of cross-modal transfer could conceivably be attributed to the species used, the training methods employed, or the stimulus dimensions manipulated. No previous study has tested the rabbit for cross-modal transfer; no other species has been tested in classical discrimination conditioning. Intermittent auditory and visual stimuli have previously been utilized in the testing of primates for cross-modal transfer, with negative (Burton \& Ettlinger, 1960) or inconclusive (Stepien \& Cordeau, 1960) results. In the latter study, transfer effects were reported from audition to vision; however, the absence of appropriate control conditions renders difficult an interpretation of the results of that study.

Additional studies with diverse species and training methods, and tests of the transfer potential of the dimensions of intensity, extensity or duration, temporal frequency, temporal pattern, and spatial pattern are required before the factors determining successful transfer of a specific discrimination across sensory modalities may be delineated.

\section{REFERENCES}

BLAKESLEE, P., \& GUNTER, R. Cross-modal transfer of discrimination learning in Cebus monkeys. Behaviour, 1966, XXVI, 76-90.

BLANK, M., ALTMAN, L.D., \& BRIDGER, W. H. Cross-modal transfer of form discrimination in preschool children. Psychonomic Science, $1968,10,51-52$.

BLANK, M., \& BRIDGER, W. H. Crossmodal transfer in nursery school children. Journal of Comparative \& Physiological Psychology, 1964, 58, 277.

BURTON, D., \& ETTLINGER, G. Cross-modal transfer of training in monkeys. Nature, 1960 , 186, 1071-1072.

ETTLINGER, G. Cross-modal transfer of training in monkeys. Behaviour, 1960, 16, 56-65.

ETTLINGER, G. Analysis of cross-modal effects and their relationship to language. In Brain mechanisms underlying speech and language. New York: Grune \& Stratton, 1967. Pp. 53-60.

GAYDOS, H. F. Intersensory transfer in the discrimination of form. American Joumal of Psychology, 1956, 69, 107-110.

GESCHWIND, N. Disconnexion syndromes in animais and man. Brain, 1965, 88, 237-294.

MONNIER, M., \& GANGLOFF, H. Atlas for stereotaxic brain research on the conscious rabbit. New York: Elsevier, 1961.

ROTHBLAT, L. A., \& WILSON, W. A., JR. Intradimensional and extradimensional shifts in the monkey within and across sensory modalities. Journal of Comparative \& Physiological Psychology, 1968, 66, 549-553.

SINHA, A. K. P., \& SINHA, S. N. Intersensory transfer in learning sequences. Journal of Experimental Psychology, 1960, 60, 180-182.

STEPIEN, L. S., \& CORDEAU, J. P. Memory in monkeys for compound stimuli. American Joumal of Psychology, 1960, 73, 388-395.

VANDERCAR, D. H., SWADLOW, H. A., ELSTER, A., \& SCHNEIDERMAN, N. Nictitating membrane with corneo-retinal transducers for conditioning in rabbits. American Psychologist, in press.

VANDERCAR, D. H., \& SCHNEIDERMAN, N. Interstimulus interval functions in different response systems during classical discrimination conditioning of rabbits. Psychonomic Science, 1967,9,9-10.

WILSON, W. A., \& SHAFFER, o. C. Intermodality transfer of specific discriminations in the monkey. Nature, 1963, $197,107$.

YEHLE, A. L. Divergences among rabbit response systems during three-tone classical discrimination conditioning. Journal of Experimental Psychology, 1968, 77, 468-473. 